\title{
Review
}

\section{Genetics and Genetic Testing in Congenital Heart Disease}

Jason R. Cowan ${ }^{1,2}$, Stephanie M. Ware ${ }^{2^{*}}$

\begin{abstract}
${ }^{1}$ University of Cincinnati College of Medicine, Cincinnati, $\mathrm{OH}$ and ${ }^{2}$ Department of Pediatrics and Herman B Wells Center for Pediatric Research, Indiana University School of Medicine, Indianapolis, IN
\end{abstract}

\author{
Jason Cowan, MS \\ Indiana University School of Medicine \\ 1044 W. Walnut Street \\ Indianapolis, IN 46202 \\ Phone: 317-274-8939 \\ Email: cowanja@iupui.edu \\ $\left.{ }^{*}\right)$ Corresponding author: \\ Stephanie M. Ware, MD, PhD \\ Indiana University School of Medicine \\ 1044 W. Walnut Street \\ Indianapolis, IN 46202 \\ Phone: 317-274-8938 \\ Fax: 317-274-8679 \\ Email: stware@iu.edu
}

This is the author's manuscript of the article published in final edited form as:

Cowan, J. R., \& Ware, S. M. (2015). Genetics and Genetic Testing in Congenital Heart Disease. Clinics in Perinatology, 42(2), 373-393. http://doi.org/10.1016/j.clp.2015.02.009 


\section{TABLE OF CONTENTS SYNOPSIS:}

In this review we provide a general overview of key morphologic, molecular, and signaling mechanisms relevant to heart development before summarizing overall progress in the molecular genetic analyses of congenital heart defects (CHDs) and providing current recommendations for clinical application of genetic testing. CHDs represent the single largest cause of infant morbidity and mortality worldwide and are, consequently, a significant source of global economic burden. Advancements in genetic testing technologies have facilitated improved diagnostics and identification of novel genetic causes, which can encompass single-gene mutations, complex chromosomal abnormalities, submicroscopic rearrangements, or whole chromosome aneuploidies. While many CHDs occur in isolation, significant proportions are associated with extra-cardiac malformations as components of wider genetic syndromes. For these reasons, genetic evaluation and counseling are considered integral components of risk assessment and clinical care.

\section{DISCLOSURE STATEMENT:}

The authors have nothing to disclose.

\section{KEY WORDS:}

Congenital heart defects, congenital heart disease, development, genetics, genetic counseling, genetic testing

\section{ABSTRACT:}

Congenital heart defects (CHDs) are structural abnormalities of the heart and great vessels that are present from birth. The presence or absence of extra-cardiac anomalies has historically been used to identify patients with possible monogenic, chromosomal, or teratogenic CHD etiologies. These distinctions remain clinically relevant, particularly with regard to management; however, identification of genetic causes in patients with presumably non-syndromic $\mathrm{CHD}$ indicates that isolated $\mathrm{CHD}$ can also be genetic in origin. In recent years, the field of cardiac genetics has benefited from a growing understanding of the complex molecular mechanisms underpinning heart development, and the extreme genetic 
heterogeneity of CHD is increasingly appreciated. Progress has been largely supported by improvements in genetic testing technology derived from worldwide efforts to accurately and economically characterize the full breadth of human genomic variation. The last fifteen years in particular have witnessed emergence and refinement of novel cytogenetic and sequencing technologies, which have proven to be enormously effective tools for both diagnosis and identification of novel CHD-causing genes. These advancements have led to an increasing need for cardiac care providers to be well versed in the molecular genetic origins of $\mathrm{CHD}$ and to have working knowledge of the benefits and limitations of available testing methods. In this review, we provide a general overview of key morphologic, molecular, and signaling mechanisms relevant to heart development before summarizing overall progress in the molecular genetic analyses of CHDs and current recommendations for clinical application of genetic testing. Particular emphasis is placed on the utility and limitations of chromosomal microarray analyses (CMAs) and on emerging clinical roles for whole exome sequencing (WES) and other next-generation sequencing (NGS) technologies.

\section{KEY POINTS:}

- Congenital heart defects (CHDs) are the largest contributor to worldwide infant morbidity and mortality.

- Known genetic causes encompass single-gene mutations, complex chromosomal abnormalities, submicroscopic rearrangements, and whole chromosome aneuploidies.

- Significant proportions of CHDs are associated with extra-cardiac malformations and/or occur as components of a genetic syndrome.

- Advancements in genetic testing technologies have facilitated improved diagnostics and identification of novel genetic causes of CHD.

- Genetic consultation and counseling is an integral component of risk assessment and clinical care. Evaluation by a geneticist is essential when a possible syndrome is suspected.

\section{INTRODUCTION:}

The impact of CHDs is profound. With a traditionally cited incidence of 8 per 1000 live births $(\sim 1 \%)$, and a need for expert cardiologic intervention in 3 of every 1000 newborns ${ }^{1}, \mathrm{CHDs}_{\text {are }}$ both the 
single largest cause of infant morbidity and mortality worldwide and a significant source of global economic burden ${ }^{2,3}$. Taking into account very high rates of CHDs in spontaneous abortuses ${ }^{4}$, and subtle or subclinical abnormalities in another $1-2 \%$ of patients ${ }^{5}$, the true overall incidence of CHDs is undoubtedly much greater. While these figures effectively convey the large global clinical impact of CHDs, they fail to communicate both the enormous diversity of phenotypes among affected individuals and the emerging understanding of the complexity of genetic and developmental etiologies.

Research into the mechanisms that regulate heart development has advanced significantly in the last twenty years. Studies employing a diverse array of model organisms including mice, frogs, and zebrafish, have facilitated major insight into normal and abnormal cardiogenesis. Furthermore, systems biology approaches designed to assess functional convergence of causative CHD genes and associated transcriptional responders (genes with altered cardiac expression) have suggested that multiple CHD risk factors are more likely to act on different components of a common functional network than to directly converge on a common genetic or molecular target ${ }^{6,7}$. These findings, coupled with an ever-expanding list of CHD-associated gene mutations ${ }^{8}$, chromosomal abnormalities ${ }^{9}$, environmental causes ${ }^{10,11}$, and epigenetic insults ${ }^{12,13}$ hint at a significant complexity to both normal heart development and $\mathrm{CHD}$ pathogenesis. In the following section, we describe current understanding of the major embryologic events that shape the developing heart. We then provide a brief overview of key signaling and molecular concepts relevant to these developmental processes. Readers desiring additional details are directed to recent comprehensive reviews ${ }^{14-21}$.

\section{Overview of heart development:}

Cell lineage is an important concept for heart development as distinct lineages support the development of specific cardiac compartments such that structural anomalies may result from dysregulation of a single cell lineage, multiple lineages, or specific inductive interactions between lineages. During the second and third weeks of human development, two mesodermal subpopulations, the first (FHF) and second (SHF) heart fields, contribute cells to the developing heart. While the FHF will ultimately contribute to the left ventricle and portions of the atria and right ventricle, the SHF supports development of the future outflow tract (OFT), ventricular septum, and the remainder of the atria and right 
ventricle $^{22}$. Cells of the FHF originate in splanchnic mesoderm of the anterior lateral plate and in response to inductive signals from adjacent endoderm become the first cardiac precursors to differentiate ${ }^{23}$. Gastrulation movements help to facilitate, positioning the cardiogenic mesoderm as bilateral folds alongside the prechordal plate. By 17-19 days, the cardiogenic folds coalesce anteriorly to form the cardiac crescent, a transient structure that will fuse and detach from the dorsal pericardial wall as a linear, bilaminar heart tube. Subsequent establishment of axial left-right asymmetries directs asymmetric growth and rightward looping of the heart tube, properly positioning the heart for future chamber and valve development. While these movements are occurring, cells from the SHF have already begun migrating from positions dorsal and posterior to the heart tube to support elongation of the arterial and venous poles. During weeks six and seven, an epithelial to mesenchymal transition populates the common atrioventricular canal and OFT with loose mesenchymal cell populations called endocardial cushions. Mature valves arise through extensive cushion remodeling and become highly stratified into distinct layers. Meanwhile, neural crest cells delaminate from the dorsal neural tube and migrate into the developing OFT to support septation of the great vessels, as well as maturation of the aortic and pulmonary valves ${ }^{24}$. Significant cardiac contributions are also made by cells of the proepicardium, which originate from venous coelomic mesothelium and support development of the future epicardium and coronary vasculature ${ }^{25}$. As development nears completion, the heart is refined into a muscular, fourchambered organ capable of regulating incoming and outgoing blood flow by way of divided inflow and outflow tracts and mature valve and conduction systems.

\section{Complex signaling and transcriptional networks regulate heart development:}

These embryonic events are tightly regulated by an extensive array of signaling pathways and transcription factors. Several recent publications have reviewed the roles of these networks throughout all major stages of cardiac development ${ }^{15-18,26}$. Therefore, the intent here will not be to reproduce these comprehensive works, but rather to highlight general mechanisms.

Every major developmental pathway contributes in some capacity to heart development (Table 1), often through extensive cross-talk with other signals or molecular factors. The impact of a particular signal can vary dramatically as development proceeds, operating positively at one stage and negatively at 
another. For example, Bmp signaling is required to induce differentiation of early cardiac progenitors, but is inhibited at later stages by Smad6a to permit Tbx2- and Tbx20-mediated chamber development ${ }^{27}$. Similarly, mouse studies have demonstrated that Wnt signals are critical for early cardiac precursor induction and proliferation, but later become inhibitory ${ }^{28,29}$. As previously mentioned, a diverse array of cardiac transcription factors acts in concert with these signals to specify, differentiate, and pattern the developing heart. Clinical genetic testing is available for many of these factors and is summarized in Table 2. The resulting web of interactions supports a highly complex milieu in which individual or multiple risk factors can act to disrupt normal heart morphogenesis. An ideal example is provided by the cardiac transcription factor, Nkx2.5, which has key functions in regulating proliferation of SHF cells through repression of Bmp2 signaling ${ }^{30}$ and in conduction system development ${ }^{31}$. Nkx2.5 also physically and functionally interacts with the major cardiac transcription factors Gata4 $4^{32}, \mathrm{Tbx}^{33}$, and Mef2c $\mathrm{c}^{34}$, each of which forms additional unique and shared connections with other molecular, genetic, and signaling components (Figure 1). Such networks also hint at "common disease-common variant" hypotheses and the implication that some CHD phenotypes may result from additive effects of multiple low-effect susceptibility alleles. Following identification of two disease-associated haplotypes in large Caucasian and African American cohorts ${ }^{35}$, the SHF marker / Lim-homeodomain transcription factor, ISL1, has emerged as a possible susceptibility candidate. Although the pathogenicity of at least one of the reported variants remains uncertain ${ }^{36,37}$, these studies highlight a growing recognition of the potential for common alleles to contribute to CHD pathogenesis.

\section{GENETICS AND RECURRENCE:}

Contemporary advancements in medical care, surgical interventions, and diagnostics have contributed to a well-characterized decrease in patient mortality and concomitant increase in CHD prevalence among patients of reproductive age $\mathrm{e}^{38-40}$. Recent analyses indicate that adults now constitute roughly two-thirds of the CHD population, representing a nearly $60 \%$ increase in CHD prevalence among adult patients since the year $2000^{38}$. The fact that the greatest increase in CHD prevalence has occurred among the 18- to 40 -year-old demographic ${ }^{38}$ has clear implications for heritability. 
Large-scale epidemiologic studies suggest that a genetic or environmental cause for CHD is identifiable in approximately $20-30 \%$ of cases $^{41-43}$. Known genetic causes are extremely heterogeneous, encompassing not only mutations in cardiac-relevant genes, but also more complex chromosomal abnormalities, submicroscopic duplications/deletions, and whole chromosome aneuploidies (Table 3). As genetic testing technologies have evolved to offer higher resolutions and greater diagnostic yields than those provided by conventional chromosomal analyses, copy number variants (CNVs) have emerged as important causes of both syndromic and non-syndromic $\mathrm{CHDs}^{9}$. Moreover, an increasing recognition of contributing environmental ${ }^{10,11}$ and epigenetic ${ }^{12,13}$ factors has revealed a previously unanticipated breadth to CHD etiology. Families with Mendelian inheritance have been useful for identifying monogenic causes, although mutations in identified genes have been infrequently detected in unrelated patient cohorts $^{44}$. Autosomal dominant, autosomal recessive, and X-linked inheritance patterns have all been reported, often in the context of additional non-cardiac malformations or syndromic disease, and each pose unique recurrence risks for affected families (Table 4). Improvements in diagnostic fidelity offered by chromosomal microarray analysis (CMA) and fluorescence in-situ hybridization (FISH) have additionally facilitated re-diagnosis of many patients with syndromic disease previously thought to have isolated $\mathrm{CHD}^{45}$. Establishment of an accurate genetic diagnosis is of critical importance, holding significant implications for not only medical management and long-term follow-up, but also for communication of relevant reproductive risks and family planning.

In general, recurrence estimates are more precise for syndromic than for isolated CHDs as inheritance patterns for many CHD-associated genetic conditions are already well characterized (Table 4). For dominantly inherited conditions, such as Noonan or Holt-Oram syndromes, individual recurrence risks for offspring with the syndrome is $50 \%$. Genetic testing is also indicated for male offspring in families with X-linked heterotaxy caused by mutations in ZIC3, as they also have a 50\% recurrence risk. Importantly not all patients with a particular syndrome will present with associated heart defects and the proportion that do can vary considerably depending on the specific diagnosis (Table 4). The presence or severity of a CHD in a parent is also not predictive of the risk for offspring. The prevalence of CHDs in a population caused by a particular syndrome ultimately depends on the likelihood of affected individuals reaching reproductive age and the new mutation rate. Consequently, despite having relatively high rates 
of associated CHDs, patients with lethal conditions such as Edwards Syndrome (Trisomy 18) or Patau Syndrome (Trisomy 13) contribute less to overall population CHD burden than patients with less severe, but more prevalent conditions.

Recurrence risks for isolated CHDs can be difficult to assign. This is especially true when the disease phenotype is complicated by reduced penetrance and variable expressivity, both of which are common. Indeed, dramatically different CHD phenotypes can be exhibited by patients with identical mutations, even among members of the same family. Nevertheless, consistent evidence of familial clustering and high heritability of isolated CHDs indicate that a strong genetic component exists, even for defects occurring without an obvious mode of inheritance ${ }^{46-49}$. Increased rates of CHDs among offspring of consanguineous unions have been noted in several populations and are commonly attributed to autosomal recessive mutations in associated disease genes (reviewed in Shieh et al ${ }^{50}$ ). Long-standing CHD models consider a large subset of CHDs to be multifactorial in origin, resulting from combined interaction of a number of distinct environmental and genetic factors ${ }^{51}$. Several large-scale epidemiological studies have examined rates of recurrence among first degree relatives of patients with isolated CHDs and collectively suggest an overall risk of 5-10\% for any CHD when either one parent or more than two siblings are affected ${ }^{52-54}$. This figure reduces to $\sim 3 \%$ with a single affected child. Risk estimates for individual defects vary, but are generally estimated in the range of 2-6\%, with higher risk afforded to children of affected mothers (Table 5). These figures are low relative to CHDs with demonstrable monogenic inheritance, but can still have potentially important implications, particularly with respect to future reproductive decision-making and prospective screening of presumably unaffected family members.

\section{DIAGNOSTIC EVALUATION:}

\section{Genetic testing algorithm for CHD:}

Genetic testing practices for CHDs have yet to be standardized in many centers and recommendations incorporating newer genetic testing technologies are, at present, poorly represented in the literature. In addition, there is evidence that genetic testing is frequently underutilized in infants with

$\mathrm{CHD}^{55,56}$. Nevertheless, the importance of genetic evaluation of patients with $\mathrm{CHD}$ has been emphasized 
in a position statement from the American Heart Association ${ }^{57}$, which cites four specific reasons to pursue testing:

(1) there may be other important organ system involvement,

(2) there may be prognostic information for clinical outcomes,

(3) there may be important genetic reproductive risks the family should know about; and

(4) there may be other family members for whom genetic testing is appropriate.

In Figure 2, we suggest a genetic testing algorithm that could be instituted in infants with CHD to provide a more comprehensive and standardized approach. This algorithm is derived from extensive clinical experience and has been used at our institution since 2009. These recommendations were explicitly created to guide cardiac care practitioners in determining appropriate genetic testing and referral strategies for cardiac intensive care unit $(\mathrm{CICU})$ patients. Practitioners should evaluate guidelines most appropriate for their institution with a goal of practicing evidence-based medicine. In our center, geneticists consult patients with syndromic or suspected syndromic CHD and genetic counselors facilitate genetic testing in patients with apparently isolated CHD for whom testing is indicated and expedite appropriate cardiac screening in first degree relatives. Ongoing multicenter registries aimed at refining the interpretation of clinical CMA findings, such as the Clinical Genome Project and the Cytogenomics of Cardiovascular Malformations Consortium, will continue to improve the diagnostic yield and interpretation of abnormal CMA in patients with CHD.

\section{Genetic services and counseling:}

Recent surveys of adult CHD populations have demonstrated that a majority of patients lack proper understanding of their personal recurrence risks, but that provision and recall of genetic information can be significantly improved by incorporating genetic services into routine cardiovascular care $^{58,59}$. Genetic counselors skilled in cardiovascular genetics have, consequently, become an invaluable clinical asset, helping to not only provide accurate recurrence risks, but also to obtain family and medical histories, facilitate appropriate genetic testing, interpret test results, make necessary subspecialty referrals, and provide attendant psychosocial support for patients and their families ${ }^{60}$. The importance of the cardiologist in promoting genetic services cannot be understated: most patients first 
hear about the possibility of genetic consultation from their cardiologist and a majority of these patients retroactively view the resulting genetics appointments positively ${ }^{58,59}$. These findings are particularly relevant in light of results from a non-scientific poll recently conducted at the 21st Annual International Adult Congenital Heart Disease (ACHD) Course which suggest that only $18 \%$ of ACHD practitioners regularly refer their patients for genetic evaluation and that only $25 \%$ regularly work alongside genetic counselors and clinical geneticists ${ }^{60}$. Continued integration of genetic professionals into existing and new cardiovascular programs will undoubtedly help to improve utilization of increasingly comprehensive and affordable genetic services.

\section{GENETIC TESTING AND EMERGING TECHNOLOGIES:}

\section{Chromosomal analyses and copy number variation:}

Genetic testing technologies have progressed considerably in recent years with novel sequencing and chromosome-based methods improving both the speed and breadth of available testing options. Although karyotyping remains the gold standard for diagnosis of aneuploidies and other large chromosomal abnormalities, cytogenetic methods such as FISH and CMA have proven invaluable in identifying microdeletion and duplication syndromes resulting from abnormalities too small to be detected by conventional chromosomal analyses (Table 6). These developments are significant: an ever-growing body of studies indicate that pathogenic CNVs are a major cause of CHDs, occurring in 3-25\% of patients with extra-cardiac abnormalities and in 3-10\% of patients with isolated heart defects (reviewed in Lander et al. ${ }^{9}$ ). In practice, the relatively limited resolutions of karyotyping and FISH have rendered them insufficient to detect a genetic cause in the majority of patients with CHDs of uncertain etiology $\mathrm{y}^{55}$ and in nearly half of all patients with syndromic $\mathrm{CHD}^{61}$. Therefore, use of CMA as a higher fidelity option for firstline CHD genetic testing has been recommended, particularly when extra-cardiac features are present and a suspected diagnosis is lacking ${ }^{61}$.

This opinion has been strongly supported by additional clinical and research studies assessing diagnostic yields in selected cohorts $55,56,62-65$. In our retrospective analysis, CMA testing detected cytogenetic abnormalities of clinical or unknown significance in 35/121 (29\%) infants with CHD ${ }^{56}$, representing rates on par with those observed in patients undergoing testing for intellectual disability ${ }^{66,67}$, 
for which CMA is already a first-line diagnostic test. Because most causal CNVs in patients with syndromic CHD are readily detectable by even low-resolution CMAs, and because significant increases in CMA resolution may not always translate to higher diagnostic yields ${ }^{68}$, physicians encountering patients with potentially syndromic phenotypes, but normal CMA results, would be prudent to rule out the possibility of a previously missed monogenic cause. Supporting this recommendation, Breckpot et al..$^{55}$ identified $7 \%$ of patients in their cohort with normal CMA results who were later found to have a singlegene disorder on follow-up.

\section{Next-generation sequencing and whole exome analysis:}

Genetic technologies are advancing at such a rapid pace that keeping abreast of methodological advancements and emerging clinical applications has become both more essential and more challenging than ever before. Arguably the most significant development in recent years has been the advent of massively parallel next-generation sequencing (NGS) technologies, which encompass an assortment of commercially and methodologically distinct services that share similar foundations in repeated sequencing of DNA fragments (reviewed in Dorn et al. ${ }^{69}$, with a focus on CHD). Millions of individual sequences ("reads") are generated in simultaneous reactions and are subsequently aligned to form a completed sequence. These techniques facilitate considerably higher depths of coverage, faster turnaround times, and increased cost-effectiveness when compared to traditional capillary-based sequencing methods ${ }^{70,71}$. Although Sanger sequencing remains the gold standard for targeted analyses of specific genes or familial mutations, it requires a priori knowledge of causative disease genes or sequences and does not contribute to novel gene discovery. Additionally, most gene panels are diseasespecific, necessitating implementation of large numbers of distinct assays. Conversely, like CMA, NGS approaches provide greater diagnostic utility for suspected genetic disease of uncertain etiology and for genetically heterogeneous conditions stemming from mutations in larger numbers of causative loci. One of the biggest benefits of this technology has been its scalability - both to large-scale whole genome/exome analyses and to smaller gene-specific targeted studies. This flexibility has initiated a paradigm shift towards adoption of NGS in both clinical and research settings and has, even in its relative infancy, greatly benefited novel disease gene discovery and patient diagnosis ${ }^{72-76}$. 
Nowhere is this shift more apparent than in the increased clinical implementation of whole exome sequencing (WES) ${ }^{73}$. In contrast to whole genome sequencing (WGS), which interrogates every base in the genome, WES specifically targets protein-encoding genomic regions and makes the implicit assumption that a significant proportion of uncharacterized genetic disease can be explained by sequence variation in coding DNA. This assumption is reasonable for many inherited conditions as most mutations resulting in Mendelian disease have been traditionally detected in protein-coding regions ${ }^{77-79}$. In addition, our current ability to interpret the functional significance of variants in non-coding regions is relatively primitive ${ }^{57}$. Importantly, WES has been demonstrated to be both robust and cost-effective ${ }^{80}$, necessitating only $5 \%$ of the total sequencing required by GWS ${ }^{81}$. Adoption of WES has consequently been swift: since its clinical debut in 2011, most major genetic centers have established WES as a testing option for patients with complex phenotypes for whom traditional single and multi-gene panels were unrevealing, prohibitively expensive, or otherwise unavailable. Although these programs are still young, initial studies have reported deleterious mutation detection rates in the range of $20-50 \% 72,82,83$, indicating significant potential for high diagnostic yields. WES has already been used successfully to identify genetic defects associated with a diverse spectrum of $\mathrm{CHDs}^{84-87}$. Interpretation of detected variants, however, remains a major challenge as WES identifies, on average, 12,000 unique coding variants per exome sequenced $^{88}$ and potentially pathogenic variants are observed even in apparently healthy individuals ${ }^{89-91}$. It is expected that reporting laboratories will perform a thorough literature review for all variants of potential clinical relevance and properly classify each as having known or uncertain significance.

While WES is clearly beneficial in multiple settings, its use as a first-tier test has generated debate, with concerns raised over not only interpretation and reporting of clinically relevant mutations, but also return of incidental findings, availability of insurance coverage, and cost effectiveness relative to existing multi-gene panels ${ }^{72,92}$. Thus, it is important that care providers familiar both with the strengths and limitations of WES and its applicability to the patient's phenotype(s) be involved in facilitating testing. It is anticipated that the already widespread application of WES will lead to improvements in existing technologies, decreasing overall costs and increased insurance coverage. 


\section{Future developments:}

To date, clinical application of NGS has largely been restricted to analysis of genomic variation. Nevertheless, the same technologies employed for DNA-based analyses can be used to interrogate a variety of other disease-relevant processes, including RNA expression, alterations in splicing, epigenetic regulation, and protein-nucleotide interactions (eg: transcription factor binding) ${ }^{93}$. These applications hold considerable future diagnostic and clinical potential and are already providing great utility for investigators applying comprehensive system-based approaches to the study of $\mathrm{CHD}^{94,95}$. The recognition that multiple independent insults are likely to contribute to at least a subset of CHD phenotypes indicate that systemsbased approaches will be necessary to understand CHD risk factor networks and properly contextualize many genetic testing results, particularly in the absence of extra-cardiac features or clear syndromic diagnoses.

\section{SUMMARY:}

The field of CHD genetics is progressing at a rapid pace. The last decade in particular has witnessed unprecedented improvements in genetic testing technologies that have greatly assisted gene discovery and helped to reshape standards of patient care. These trends are likely to continue as testing costs continue to decline and genetic services become further integrated into new and existing cardiovascular programs. With the functional significance of much of the genome still undefined and the mechanisms driving both normal and abnormal heart development incompletely understood, interpretation and reporting of clinically relevant mutations will remain a major challenge for the foreseeable future. Accordingly, clinical geneticists and genetic counselors will need to play increasingly key roles in patient care, ensuring accurate diagnosis and effective communication of inheritance and recurrence risks. Despite, or perhaps because of, such challenges, this new era of unbiased, genomeand exome-based testing is an exciting one. Recent efforts integrating results from animal modeling studies with systems biology approaches indicate great potential for future developmental research, while collaborative endeavors such as the National Heart, Lung, and Blood Institute's (NHLBI) Bench to Bassinet program (http://www.benchtobassinet.com/) aim to bridge the gap between basic research and clinical practice. The wealth of genetic data anticipated from these and other forward-thinking studies 
promise to power novel hypotheses for future experimentation and to generate new avenues for potential therapeutic intervention. 
Best Practices Box

\section{What is the current practice?}

Genetic Testing in Congenital Heart Disease:

- Genetic testing practices for CHDs have yet to be standardized in many centers.

- Recommendations incorporating newer genetic testing methods are poorly represented in the literature.

- Genetic testing is frequently underutilized for infants with CHD.

Genetic Testing Options:

- Karyotyping is the gold standard for diagnosis of aneuploidies and other large chromosomal abnormalities.

- Chromosomal microarray (CMA) and fluorescence in situ hybridization (FISH) permit identification of microdeletion and duplication syndromes resulting from abnormalities too small to be detected by conventional chromosome analyses.

- Sanger sequencing is the gold standard for targeted molecular analysis of specific genes or familial mutations. Gene panels are available for many CHD-associated syndromes, but are limited by knowledge of causative disease genes.

\section{What changes in current practice are likely to improve outcomes?}

- Continued integration of genetic testing services into cardiovascular practice will improve diagnostic and prognostic accuracy and will support risk assessment and family planning initiatives.

- Emerging next generation sequencing (NGS) technologies promise to greatly benefit patient diagnosis and gene discovery efforts.

\section{Is there a Clinical Algorithm?}

- $\quad$ Our proposed genetic testing algorithm is presented in Figure 2.

- In our center, geneticists consult patients with known or suspected syndromic CHD and genetic counselors facilitate genetic testing in patients with apparently isolated CHD and expedite appropriate screening in first degree relatives.

\section{Major Recommendations:}

Genetic testing and referral decisions should be determined based on the nature of the cardiac defect:

1. Patients with defects suggesting a common chromosomal aneuploidy should undergo karyotyping and FISH testing. The patient should be referred for further genetic evaluation.

2. Patients with multiple congenital anomalies, neurological findings, developmental delay, and/or dysmorphic features should also be referred for further genetics evaluation.

3. Depending on the level of suspicion, patients with conotruncal defects should undergo CMA and/or targeted FISH testing for 22q11.2 deletion syndrome.

4. A detailed pedigree should be obtained and CMA testing should be pursued for patients with apparently non-syndromic LVOTO, RVOTO, AVSD, heterotaxy, or other complex defects. Abnormal test results warrant referral for further genetics evaluation.

Rating for the Strength of the Evidence:

\section{References:}

Pierpont ME, Basson CT, Benson DW, Jr., et al. Genetic basis for congenital heart defects: current knowledge. Circulation 2007;115:3015-38 (American Heart Association Position Statement).

\section{Summary:}

- Improvements in genetic testing technologies have assisted gene discovery and helped to reshape standards of patient care. These trends are expected to continue as testing costs decline and genetic services become further integrated into new and existing cardiovascular programs. 


\section{REFERENCES:}

1. Hoffman JI,Kaplan S. The incidence of congenital heart disease. J Am Coll Cardiol 2002;39:1890-900.

2. Centers for Disease C,Prevention. Hospital stays, hospital charges, and in-hospital deaths among infants with selected birth defects--United States, 2003. MMWR Morb Mortal Wkly Rep 2007;56:25-9.

3. Boneva RS, Botto LD, Moore CA, et al. Mortality associated with congenital heart defects in the United States: trends and racial disparities, 1979-1997. Circulation 2001;103:2376-81.

4. Hoffman JI. Incidence of congenital heart disease: II. Prenatal incidence. Pediatr Cardiol 1995;16:15565.

5. Srivastava D. Making or breaking the heart: from lineage determination to morphogenesis. Cell 2006;126:1037-48.

6. Lage K, Greenway SC, Rosenfeld JA, et al. Genetic and environmental risk factors in congenital heart disease functionally converge in protein networks driving heart development. Proc Natl Acad Sci U S A 2012;109:14035-40.

7. Lage K, Mollgard K, Greenway S, et al. Dissecting spatio-temporal protein networks driving human heart development and related disorders. Mol Syst Biol 2010;6:381.

8. Stenson PD, Ball EV, Mort M, et al. Human Gene Mutation Database (HGMD): 2003 update. Hum Mutat 2003;21:577-81.

9. Lander J,Ware S. Copy Number Variation in Congenital Heart Defects. Curr Genet Med Rep 2014; Advance online publication. doi:10.1007/s40142-014-0049-3.

10. Jenkins KJ, Correa A, Feinstein JA, et al. Noninherited risk factors and congenital cardiovascular defects: current knowledge: a scientific statement from the American Heart Association Council on Cardiovascular Disease in the Young: endorsed by the American Academy of Pediatrics. Circulation 2007;115:2995-3014.

11. Kuciene R,Dulskiene V. Selected environmental risk factors and congenital heart defects. Medicina (Kaunas) 2008;44:827-32.

12. Vallaster $M$, Vallaster $C D, W u$ SM. Epigenetic mechanisms in cardiac development and disease. Acta Biochim Biophys Sin (Shanghai) 2012;44:92-102.

13. Chang CP,Bruneau BG. Epigenetics and cardiovascular development. Annu Rev Physiol 2012;74:4168.

14. Lalani SR,Belmont JW. Genetic basis of congenital cardiovascular malformations. Eur J Med Genet 2014;

15. Bruneau BG. Signaling and transcriptional networks in heart development and regeneration. Cold Spring Harb Perspect Biol 2013;5:a008292.

16. Rochais F, Mesbah K,Kelly RG. Signaling pathways controlling second heart field development. Circ Res 2009;104:933-42.

17. Rana MS, Christoffels VM,Moorman AF. A molecular and genetic outline of cardiac morphogenesis. Acta Physiol (Oxf) 2013;207:588-615.

18. Kodo K,Yamagishi H. A decade of advances in the molecular embryology and genetics underlying congenital heart defects. Circ J 2011;75:2296-304.

19. Fahed AC, Gelb BD, Seidman JG, et al. Genetics of congenital heart disease: the glass half empty. Circ Res 2013;112:707-20.

20. Wagner M,Siddiqui MA. Signal transduction in early heart development (II): ventricular chamber specification, trabeculation, and heart valve formation. Exp Biol Med (Maywood) 2007;232:86680.

21. Wagner M,Siddiqui MA. Signal transduction in early heart development (I): cardiogenic induction and heart tube formation. Exp Biol Med (Maywood) 2007;232:852-65. 
22. Meilhac SM, Esner M, Kelly RG, et al. The clonal origin of myocardial cells in different regions of the embryonic mouse heart. Dev Cell 2004;6:685-98.

23. Schultheiss TM, Xydas S, Lassar AB. Induction of avian cardiac myogenesis by anterior endoderm. Development 1995;121:4203-14.

24. Jiang $X$, Rowitch $\mathrm{DH}$, Soriano $\mathrm{P}$, et al. Fate of the mammalian cardiac neural crest. Development 2000;127:1607-16.

25. Ratajska A, Czarnowska E,Ciszek B. Embryonic development of the proepicardium and coronary vessels. Int J Dev Biol 2008;52:229-36.

26. McCulley DJ,Black BL. Transcription factor pathways and congenital heart disease. Curr Top Dev Biol 2012;100:253-77.

27. de Pater $\mathrm{E}$, Ciampricotti $\mathrm{M}$, Priller $\mathrm{F}$, et al. Bmp signaling exerts opposite effects on cardiac differentiation. Circ Res 2012;110:578-87.

28. Naito AT, Shiojima I, Akazawa H, et al. Developmental stage-specific biphasic roles of Wnt/betacatenin signaling in cardiomyogenesis and hematopoiesis. Proc Natl Acad Sci U S A 2006;103:19812-7.

29. Kwon C, Arnold J, Hsiao EC, et al. Canonical Wnt signaling is a positive regulator of mammalian cardiac progenitors. Proc Natl Acad Sci U S A 2007;104:10894-9.

30. Prall OW, Menon MK, Solloway MJ, et al. An Nkx2-5/Bmp2/Smad1 negative feedback loop controls heart progenitor specification and proliferation. Cell 2007;128:947-59.

31. Jay PY, Harris BS, Maguire CT, et al. Nkx2-5 mutation causes anatomic hypoplasia of the cardiac conduction system. J Clin Invest 2004;113:1130-7.

32. Lee $\mathrm{Y}$, Shioi $\mathrm{T}$, Kasahara $\mathrm{H}$, et al. The cardiac tissue-restricted homeobox protein Csx/Nkx2.5 physically associates with the zinc finger protein GATA4 and cooperatively activates atrial natriuretic factor gene expression. Mol Cell Biol 1998;18:3120-9.

33. Hiroi Y, Kudoh S, Monzen K, et al. Tbx5 associates with Nkx2-5 and synergistically promotes cardiomyocyte differentiation. Nat Genet 2001;28:276-80.

34. Vincentz JW, Barnes RM, Firulli BA, et al. Cooperative interaction of Nkx2.5 and Mef2c transcription factors during heart development. Dev Dyn 2008;237:3809-19.

35. Stevens KN, Hakonarson H, Kim CE, et al. Common variation in ISL1 confers genetic susceptibility for human congenital heart disease. PLoS One 2010;5:e10855.

36. Cresci M, Vecoli C, Foffa I, et al. Lack of association of the 3'-UTR polymorphism (rs1017) in the ISL1 gene and risk of congenital heart disease in the white population. Pediatr Cardiol 2013;34:93841.

37. Xue L, Wang $X, X u$ J, et al. ISL1 common variant rs1017 is not associated with susceptibility to congenital heart disease in a Chinese population. Genet Test Mol Biomarkers 2012;16:679-83.

38. Marelli AJ, Ionescu-Ittu R, Mackie AS, et al. Lifetime Prevalence of Congenital Heart Disease in the General Population from 2000 to 2010. Circulation 2014;

39. Engelfriet $P$, Boersma $E$, Oechslin $E$, et al. The spectrum of adult congenital heart disease in Europe: morbidity and mortality in a 5 year follow-up period. The Euro Heart Survey on adult congenital heart disease. Eur Heart J 2005;26:2325-33.

40. Marelli AJ, Mackie AS, lonescu-Ittu R, et al. Congenital heart disease in the general population: changing prevalence and age distribution. Circulation 2007;115:163-72.

41. Ferencz C, Boughman JA, Neill CA, et al. Congenital cardiovascular malformations: questions on inheritance. Baltimore-Washington Infant Study Group. J Am Coll Cardiol 1989;14:756-63.

42. Grech V,Gatt M. Syndromes and malformations associated with congenital heart disease in a population-based study. Int J Cardiol 1999;68:151-6.

43. Meberg A, Hals J,Thaulow E. Congenital heart defects--chromosomal anomalies, syndromes and extracardiac malformations. Acta Paediatr 2007;96:1142-5. 
44. Posch MG, Perrot A, Schmitt K, et al. Mutations in GATA4, NKX2.5, CRELD1, and BMP4 are infrequently found in patients with congenital cardiac septal defects. Am J Med Genet $A$ 2008;146A:251-3.

45. Erdogan F, Larsen LA, Zhang L, et al. High frequency of submicroscopic genomic aberrations detected by tiling path array comparative genome hybridisation in patients with isolated congenital heart disease. J Med Genet 2008;45:704-9.

46. Burn J, Brennan P, Little J, et al. Recurrence risks in offspring of adults with major heart defects: results from first cohort of British collaborative study. Lancet 1998;351:311-6.

47. Cripe L, Andelfinger G, Martin L, et al. Bicuspid aortic valve is heritable. J Am Coll Cardiol 2004;44:138-43.

48. Hinton RB, Jr., Martin $\amalg$, Tabangin ME, et al. Hypoplastic left heart syndrome is heritable. J Am Coll Cardiol 2007; 50:1590-5.

49. Insley J. The heritability of congenital heart disease. Br Med J (Clin Res Ed) 1987;294:662-3.

50. Shieh JT, Bittles AH,Hudgins L. Consanguinity and the risk of congenital heart disease. Am J Med Genet A 2012;158A:1236-41.

51. Nora JJ. Multifactorial inheritance hypothesis for the etiology of congenital heart diseases. The genetic-environmental interaction. Circulation 1968;38:604-17.

52. Calcagni G, Digilio MC, Sarkozy A, et al. Familial recurrence of congenital heart disease: an overview and review of the literature. Eur J Pediatr 2007;166:111-6.

53. Nora JJ. From generational studies to a multilevel genetic-environmental interaction. J Am Coll Cardiol 1994;23:1468-71.

54. Nora JJ,Nora AH. Update on counseling the family with a first-degree relative with a congenital heart defect. Am J Med Genet 1988;29:137-42.

55. Breckpot J, Thienpont B, Peeters $\mathrm{H}$, et al. Array comparative genomic hybridization as a diagnostic tool for syndromic heart defects. J Pediatr 2010;156:810-7, 817 e1-817 e4.

56. Connor JA, Hinton RB, Miller EM, et al. Genetic testing practices in infants with congenital heart disease. Congenit Heart Dis 2014;9:158-67.

57. Pierpont ME, Basson CT, Benson DW, Jr., et al. Genetic basis for congenital heart defects: current knowledge: a scientific statement from the American Heart Association Congenital Cardiac Defects Committee, Council on Cardiovascular Disease in the Young: endorsed by the American Academy of Pediatrics. Circulation 2007;115:3015-38.

58. van Engelen $\mathrm{K}$, Baars MJ, Felix JP, et al. The value of the clinical geneticist caring for adults with congenital heart disease: diagnostic yield and patients' perspective. Am J Med Genet A 2013;161A:1628-37.

59. van Engelen K, Baars MJ, van Rongen LT, et al. Adults with congenital heart disease: patients' knowledge and concerns about inheritance. Am J Med Genet A 2011;155A:1661-7.

60. Parrott A,Ware SM. The Role of the Geneticist and Genetic Counselor in an ACHD Clinic. Prog Pediatr Cardiol 2012;34:15-20.

61. Breckpot J, Thienpont B, Arens $\mathrm{Y}$, et al. Challenges of interpreting copy number variation in syndromic and non-syndromic congenital heart defects. Cytogenet Genome Res 2011;135:2519.

62. Baker K, Sanchez-de-Toledo J, Munoz R, et al. Critical congenital heart disease--utility of routine screening for chromosomal and other extracardiac malformations. Congenit Heart Dis 2012;7:145-50.

63. Richards AA, Santos L, Nichols HA, et al. Cryptic chromosomal abnormalities identified in children with congenital heart disease. Pediatr Res 2008;64:358-63. 
64. Thienpont B, Mertens L, de Ravel T, et al. Submicroscopic chromosomal imbalances detected by array-CGH are a frequent cause of congenital heart defects in selected patients. Eur Heart J 2007;28:2778-84.

65. Goldmuntz E, Paluru P, Glessner J, et al. Microdeletions and microduplications in patients with congenital heart disease and multiple congenital anomalies. Congenit Heart Dis 2011;6:592-602.

66. Schoumans J, Ruivenkamp C, Holmberg E, et al. Detection of chromosomal imbalances in children with idiopathic mental retardation by array based comparative genomic hybridisation (arrayCGH). J Med Genet 2005;42:699-705.

67. Thuresson AC, Bondeson ML, Edeby $\mathrm{C}$, et al. Whole-genome array-CGH for detection of submicroscopic chromosomal imbalances in children with mental retardation. Cytogenet Genome Res 2007;118:1-7.

68. Wincent J, Anderlid BM, Lagerberg M, et al. High-resolution molecular karyotyping in patients with developmental delay and/or multiple congenital anomalies in a clinical setting. Clin Genet 2011;79:147-57.

69. Dorn C, Grunert M,Sperling SR. Application of high-throughput sequencing for studying genomic variations in congenital heart disease. Brief Funct Genomics 2014;13:51-65.

70. Shendure J,Ji H. Next-generation DNA sequencing. Nat Biotechnol 2008;26:1135-45.

71. Mardis ER. A decade's perspective on DNA sequencing technology. Nature 2011;470:198-203.

72. Atwal PS, Brennan ML, Cox R, et al. Clinical whole-exome sequencing: are we there yet? Genet Med 2014; Advance online publication. doi: 10.1038/gim.2014.10.

73. Bamshad MJ, Ng SB, Bigham AW, et al. Exome sequencing as a tool for Mendelian disease gene discovery. Nat Rev Genet 2011;12:745-55.

74. Iglesias A, Anyane-Yeboa K, Wynn J, et al. The usefulness of whole-exome sequencing in routine clinical practice. Genet Med 2014; Advance online publication. doi: 10.1038/gim.2014.58.

75. Levenson D. Whole-exome sequencing emerges as clinical diagnostic tool: testing method proves useful for diagnosing wide range of genetic disorders. Am J Med Genet A 2014;164A:ix-x.

76. Schuler BA, Prisco SZ,Jacob HJ. Using whole exome sequencing to walk from clinical practice to research and back again. Circulation 2013;127:968-70.

77. Chen CT, Wang JC,Cohen BA. The strength of selection on ultraconserved elements in the human genome. Am J Hum Genet 2007;80:692-704.

78. Kryukov GV, Pennacchio LA,Sunyaev SR. Most rare missense alleles are deleterious in humans: implications for complex disease and association studies. Am J Hum Genet 2007;80:727-39.

79. Ahituv N, Zhu Y, Visel A, et al. Deletion of ultraconserved elements yields viable mice. PLoS Biol 2007;5:e234.

80. Lupski JR, Gonzaga-Jauregui C, Yang Y, et al. Exome sequencing resolves apparent incidental findings and reveals further complexity of SH3TC2 variant alleles causing Charcot-Marie-Tooth neuropathy. Genome Med 2013;5:57.

81. Ng SB, Turner EH, Robertson PD, et al. Targeted capture and massively parallel sequencing of 12 human exomes. Nature 2009;461:272-6.

82. Yang Y, Muzny DM, Reid JG, et al. Clinical whole-exome sequencing for the diagnosis of mendelian disorders. N Engl J Med 2013;369:1502-11.

83. Need AC, Shashi V, Hitomi Y, et al. Clinical application of exome sequencing in undiagnosed genetic conditions. J Med Genet 2012;49:353-61.

84. Al Turki S, Manickaraj AK, Mercer CL, et al. Rare variants in NR2F2 cause congenital heart defects in humans. Am J Hum Genet 2014;94:574-85.

85. Arrington $\mathrm{CB}$, Bleyl SB, Matsunami N, et al. Exome analysis of a family with pleiotropic congenital heart disease. Circ Cardiovasc Genet 2012;5:175-82. 
86. Francis C, Prapa S, Abdulkareem N, et al. 95 Identification of likely pathogenic variants in patients with bicuspid aortic valve: correlation of complex genotype with a more severe aortic phenotype. Heart 2014;100 Suppl 3:A55-6.

87. Tariq $\mathrm{M}$, Belmont JW, Lalani S, et al. SHROOM3 is a novel candidate for heterotaxy identified by whole exome sequencing. Genome Biol 2011;12:R91.

88. Ng PC, Levy S, Huang J, et al. Genetic variation in an individual human exome. PLoS Genet 2008;4:e1000160.

89. Marth GT, Yu F, Indap AR, et al. The functional spectrum of low-frequency coding variation. Genome Biol 2011;12:R84.

90. Tennessen JA, Bigham AW, O'Connor TD, et al. Evolution and functional impact of rare coding variation from deep sequencing of human exomes. Science 2012;337:64-9.

91. Li Y, Vinckenbosch N, Tian G, et al. Resequencing of 200 human exomes identifies an excess of lowfrequency non-synonymous coding variants. Nat Genet 2010;42:969-72.

92. Kaye J, Boddington P, de Vries J, et al. Ethical implications of the use of whole genome methods in medical research. Eur J Hum Genet 2010;18:398-403.

93. Morozova O,Marra MA. Applications of next-generation sequencing technologies in functional genomics. Genomics 2008;92:255-64.

94. MacLellan WR, Wang Y,Lusis AJ. Systems-based approaches to cardiovascular disease. Nat Rev Cardiol 2012;9:172-84.

95. Sperling SR. Systems biology approaches to heart development and congenital heart disease. Cardiovasc Res 2011;91:269-78.

96. van der Bom T, Zomer AC, Zwinderman AH, et al. The changing epidemiology of congenital heart disease. Nat Rev Cardiol 2011;8:50-60.

97. Roos-Hesselink JW, Kerstjens-Frederikse WS, Meijboom BR, et al. Inheritance of congenital heart disease. Netherlands Heart Journal 2005;13:4.

98. Blue GM, Kirk EP, Sholler GF, et al. Congenital heart disease: current knowledge about causes and inheritance. Med J Aust 2012;197:155-9.

99. Bernier FP,Spaetgens R. The geneticist's role in adult congenital heart disease. Cardiol Clin 2006;24:557-69, v-vi. 
Figure 1: NKX2-5 forms a complex network of physical and genetic interactions with GATA4, TBX5, and MEF2C. The network diagram was generated using GeneMANIA software (http://www.genemania.org/). "GATA4, NKX-5, TBX5, and MEF2C" were used as query terms and results were weighted towards "biological process". To maximize readability, output was restricted to 20 related genes.

Figure 2: Proposed genetic testing algorithm for CHD. Genetic testing and referral decisions are determined based on the nature of the cardiac defect. If the defect is associated with features suggestive of a common chromosomal aneuploidy, karyotyping and FISH are undertaken and the patient is referred for evaluation by genetics. Likewise, patients with multiple congenital anomalies, neurological findings, developmental delay, and/or dysmorphic features all receive a genetics referral. Patients with isolated CHDs are stratified based on the nature of their individual phenotype. Those with conotruncal defects have testing for 22q11.2 deletion syndrome via CMA or targeted FISH testing depending on the level of suspicion. Apparently non-syndromic patients with LVOTO, RVOTO, AVSD, heterotaxy, and other complex defects have a detailed pedigree and CMA testing, as indicated. First degree relatives of patients with LVOTO defects are referred for cardiac screening. Abbreviations: ASD = atrial septal defect, $\mathrm{AVSD}=$ atrioventricular septal defect, $\mathrm{CMA}=$ chromosomal microarray analysis, $\mathrm{FISH}=$ fluorescence in situ hybridization, IAA = interrupted aortic arch, LVOTO/RVOTO = left/right ventricular outflow tract obstruction, TOF $=$ Tetralogy of Fallot, $\mathrm{VSD}=$ ventricular septal defect, $\operatorname{TrA}=$ truncus arteriosus 
Table 1: Signaling pathways involved in heart development

\begin{tabular}{|c|c|}
\hline Pathway & Developmental Role(s) \\
\hline BMP & $\begin{array}{l}\text { Cardiac mesoderm induction } \\
\text { Cardiac progenitor specification / differentiation } \\
\text { OFT septation } \\
\text { Myocardial trabeculation } \\
\text { AV canal development } \\
\text { EC / valve development }\end{array}$ \\
\hline EGF & $\begin{array}{l}\text { Myocardial trabeculation } \\
\text { EC / valve development }\end{array}$ \\
\hline FGF & $\begin{array}{l}\text { Cardiac mesoderm induction } \\
\text { Cardiac progenitor specification / differentiation } \\
\text { SHF development } \\
\text { EC / valve development }\end{array}$ \\
\hline Hedgehog & $\begin{array}{l}\text { Cardiac progenitor specification } \\
\text { Heart looping / L-R patterning } \\
\text { SHF development / OFT septation } \\
\text { AV septation } \\
\text { EC / valve development } \\
\text { NCC development }\end{array}$ \\
\hline MAPK & $\begin{array}{l}\text { Cardiac mesoderm induction } \\
\text { OFT development } \\
\text { EC / valve development } \\
\text { NCC development }\end{array}$ \\
\hline Notch & $\begin{array}{l}\text { Cardiac progenitor specification / differentiation } \\
\text { Heart looping / L-R patterning } \\
\text { OFT development } \\
\text { Myocardial trabeculation } \\
\text { AV canal / EC / valve development } \\
\text { NCC development }\end{array}$ \\
\hline $\mathrm{RA}$ & $\begin{array}{l}\text { Cardiac progenitor proliferation } \\
\text { Heart tube formation / looping } \\
\text { A-P cardiac patterning } \\
\text { SHF development } \\
\text { Myocardial trabeculation }\end{array}$ \\
\hline TGF- $\beta$ / Nodal & $\begin{array}{l}\text { Cardiac mesoderm induction } \\
\text { Cardiac progenitor specification } \\
\text { Heart looping / L-R patterning }\end{array}$ \\
\hline VEGF & $\begin{array}{l}\text { OFT septation } \\
\text { EC / valve development }\end{array}$ \\
\hline Wnt (Canonical) & $\begin{array}{l}\text { Cardiac progenitor proliferation } \\
\text { OFT septation } \\
\text { EC / valve development }\end{array}$ \\
\hline Wnt (Non-canonical) & $\begin{array}{l}\text { Cardiac mesoderm induction } \\
\text { Cardiac progenitor specification } \\
\text { SHF / OFT development }\end{array}$ \\
\hline
\end{tabular}

Abbreviations: $\mathrm{A}-\mathrm{P}=$ anterior-posterior, $\mathrm{AV}=$ atrioventricular, $\mathrm{BMP}=$ bone morphogenetic protein, $\mathrm{EC}=$ endocardial cushion, EGF = epidermal growth factor, ERK = extracellular signal-regulated kinase, FGF = fibroblast growth factor, $\mathrm{L}-\mathrm{R}=$ left-right, $\mathrm{MAPK}=$ mitogen-activated protein kinase, $\mathrm{NCC}=$ neural crest cell, OFT = outflow tract, RA = retinoic acid, SHF = second heart field, TGF- $\beta=$ transforming growth factor-beta, VEGF = vascular endothelial growth factor, $\mathrm{Wnt}=$ wingless type 
Table 2: Clinical testing availability for transcription factors associated with CHD

\begin{tabular}{|c|c|c|c|}
\hline Gene & Protein & Associated Syndrome(s) & $\begin{array}{l}\text { Clinical Testing } \\
\quad \text { Available }^{1}\end{array}$ \\
\hline ALX3 & Aristaless-Like Homeobox 3 & Frontonasal Dysplasia & Yes \\
\hline ANKRD1 & Ankyrin Repeat Domain 1 & Dilated Cardiomyopathy & Yes \\
\hline ARX & Aristaless Related Homeobox & $\begin{array}{c}\text { X-Linked Lissencephaly with } \\
\text { Ambiguous Genitalia; Epileptic } \\
\text { Encephalopathy, Early Infantile, 1; } \\
\text { Agenesis of Corpus Callosum with } \\
\text { Abnormal Genitalia }\end{array}$ & Yes \\
\hline CITED2 & $\begin{array}{c}\text { Cbp/P300-Interacting } \\
\text { Transactivator, With Glu/Asp-Rich } \\
\text { Carboxy-Terminal Domain, } 2\end{array}$ & Isolated CHD & No \\
\hline ETS1 & $\begin{array}{l}\text { V-Ets Avian Erythroblastosis } \\
\text { Virus E26 Oncogene Homolog } 1\end{array}$ & Isolated CHD & No \\
\hline EVC1 & Ellis Van Creveld Syndrome 1 & $\begin{array}{c}\text { Ellis-van Creveld Syndrome; Weyers } \\
\text { Acrofacial Dystosis }\end{array}$ & Yes \\
\hline EVC2 & Ellis Van Creveld Syndrome 2 & Ellis-van Creveld Syndrome & Yes \\
\hline EYA1 & Eyes Absent Homolog 1 & $\begin{array}{l}\text { Branchiootorenal Syndrome; } \\
\text { Otofaciocervical Syndrome }\end{array}$ & Yes \\
\hline FOXC1 & Forkhead Box C1 & $\begin{array}{l}\text { Iridogoniodysgenesis, Type 1; } \\
\text { Axenfeld-Rieger Syndrome, Type } 3\end{array}$ & Yes \\
\hline FOXC2 & Forkhead Box C2 & Lymphedema-Distichiasis Syndrome & Yes \\
\hline FOXH1 & Forkhead Box H1 & Holoprosencephaly & Yes \\
\hline FOXP1 & Forkhead Box P1 & $\begin{array}{l}\text { Mental Retardation with Language } \\
\text { Impairment and Autistic Features }\end{array}$ & Yes \\
\hline GATA4 & GATA Binding Protein 4 & Isolated CHD & Yes \\
\hline GATA5 & GATA Binding Protein 5 & Isolated CHD & Yes \\
\hline GATA6 & GATA Binding Protein 6 & Isolated CHD & Yes \\
\hline HAND1 & $\begin{array}{l}\text { Heart And Neural Crest } \\
\text { Derivatives Expressed } 1 \\
\end{array}$ & Isolated CHD & No \\
\hline HAND2 & $\begin{array}{l}\text { Heart And Neural Crest } \\
\text { Derivatives Expressed } 2\end{array}$ & Isolated CHD & No \\
\hline
\end{tabular}




\begin{tabular}{|c|c|c|c|}
\hline HOXA1 & Homeobox A1 & $\begin{array}{c}\text { Athabaskan Brain Stem Dysgenesis } \\
\text { Syndrome; Bosley-Salih-Alorainy } \\
\text { Syndrome }\end{array}$ & Yes \\
\hline IRX4 & Iroquois Homeobox 4 & Isolated CHD & No \\
\hline MED12 & Mediator Complex Subunit 12 & $\begin{array}{c}\text { FG Syndrome Type 1; Lujan-Fryns } \\
\text { Syndrome }\end{array}$ & Yes \\
\hline MED13L & $\begin{array}{l}\text { Mediator Complex Subunit 13- } \\
\text { Like }\end{array}$ & Isolated CHD & No \\
\hline MEF2C & Myocyte Enhancer Factor 2C & $\begin{array}{l}\text { Mental Retardation, Stereotypic } \\
\text { Movements, Epilepsy, and/or } \\
\text { Cerebral Malformations }\end{array}$ & Yes \\
\hline MESP1 & Mesoderm Posterior 1 Homolog & Isolated CHD & No \\
\hline MYCN & $\begin{array}{c}\text { V-Myc Avian Myelocytomatosis } \\
\text { Viral Oncogene Neuroblastoma } \\
\text { Derived Homolog }\end{array}$ & Feingold Syndrome 1 & Yes \\
\hline MYOCD & Myocardin & Isolated CHD & No \\
\hline NFATC1 & $\begin{array}{l}\text { Nuclear Factor Of Activated T- } \\
\text { Cells, Cytoplasmic, Calcineurin- } \\
\text { Dependent } 1\end{array}$ & Isolated CHD & No \\
\hline NKX2-5 & NK2 Homeobox 5 & Isolated CHD & Yes \\
\hline NKX2-6 & NK2 Homeobox 6 & Isolated CHD & Yes \\
\hline PAX3 & Paired Box 3 & $\begin{array}{l}\text { Waardenburg Syndrome Type I, } \\
\text { Type 3; Craniofacial-Deafness-Hand } \\
\text { Syndrome }\end{array}$ & Yes \\
\hline PITX2 & Paired-Like Homeodomain 2 & Axenfeld-Rieger Syndrome & Yes \\
\hline SALL1 & Spalt-Like Transcription Factor 1 & Townes-Brocks Syndrome & Yes \\
\hline SALL4 & Spalt-Like Transcription Factor 4 & $\begin{array}{l}\text { Duane-Radial Ray Syndrome; Acro- } \\
\text { Renal-Ocular Syndrome }\end{array}$ & Yes \\
\hline SETBP1 & SET Binding Protein 1 & $\begin{array}{l}\text { Schinzel-Giedion Midface Retraction } \\
\text { Syndrome }\end{array}$ & Yes \\
\hline SIX6 & SIX Homeobox 6 & Microphthalmia with Cataract 2 & Yes \\
\hline SoX2 & Sex Determining Region Y-Box 2 & Anophthalmia/Microphthalmia & Yes \\
\hline SOX9 & Sex Determining Region Y-Box 9 & Campomelic Dysplasia & Yes \\
\hline TBX1 & T-Box 1 & 22q11.2 Deletion Syndrome & Yes \\
\hline TBX3 & T-Box 3 & Ulnar-Mammary Syndrome & Yes \\
\hline TBX5 & T-Box 5 & Holt-Oram Syndrome & Yes \\
\hline TBX20 & T-Box 20 & Isolated CHD & Yes \\
\hline TFAP2B & Transcription Factor AP-2 Beta & Char Syndrome & Yes \\
\hline
\end{tabular}




\begin{tabular}{|c|c|c|c|} 
& Tumor Protein P63 & $\begin{array}{c}\text { ADULT syndrome, Ectrodactyly, } \\
\text { ectodermal dysplasia, and cleft } \\
\text { lip/palate syndrome 3; Hay-Wells } \\
\text { syndrome; Limb-mammary } \\
\text { Syndrome; Rapp-Hodgkin syndrome }\end{array}$ & Yes \\
\hline TWIST1 & $\begin{array}{c}\text { Twist Family BHLH Transcription } \\
\text { Factor 1 }\end{array}$ & Saethre-Chotzen Syndrome & Yes \\
\hline ZEB2 & $\begin{array}{c}\text { Zinc Finger E-Box Binding } \\
\text { Homeobox 2 }\end{array}$ & Mowat-Wilson Syndrome & Yes \\
\hline ZFPM2 & $\begin{array}{c}\text { Zinc Finger Protein, FOG Family } \\
\text { Member 2 }\end{array}$ & Yes \\
\hline ZIC3 & Zic Family Member 3 & Heterotaxy Syndrome; VACTERL & Yes \\
\hline
\end{tabular}

${ }^{1}$ Accurate as of 7/24/2014; Source: Genetests (http://www.genetests.org/) 
Table 3: Etiology of congenital heart disease

\begin{tabular}{|c|c|c|}
\hline Genetic Cause & \% CHD Attributed & References \\
\hline Single gene & $3-5 \%$ & 96 \\
\hline Chromosomal / Aneuploidy & $8-10 \%$ & 96,97 \\
\hline Copy Number Variation & $3-25 \%$ (Syndromic), 3-10\% (Isolated) & 9 \\
\hline Environmental & 2\% & 11 \\
\hline Multifactorial & Unknown, estimated 80-85\% & 97,98 \\
\hline
\end{tabular}


Table 4: Examples of common syndromes associated with CHD

\begin{tabular}{|c|c|c|c|c|}
\hline Syndrome & $\begin{array}{l}\text { Live-birth } \\
\text { Prevalence }\end{array}$ & Genetic Etiology & Inheritance $^{1}$ & $\begin{array}{l}\text { Cardiac Phenotype (\% } \\
\text { Patients with CHD) }\end{array}$ \\
\hline \multicolumn{5}{|l|}{ Aneuploidies } \\
\hline $\begin{array}{l}\text { Down } \\
\text { syndrome }\end{array}$ & $1 / 1000$ & Trisomy 21 & Typically sporadic (RR = $\leq 1 \%)$ & $\begin{array}{l}\text { ASD, AVC, PDA, VSD (40- } \\
50 \%)\end{array}$ \\
\hline $\begin{array}{l}\text { Turner } \\
\text { syndrome }\end{array}$ & $\begin{array}{l}1 / 2,000 \\
1 / 5,000\end{array}$ & $45, X$ & Typically sporadic (RR = $\leq 1 \%)$ & $\begin{array}{l}\text { Left-sided defects: Aortic } \\
\text { dilatation, AS, BAV, CoA, } \\
\text { HLHS, PAPVD (15-50\%) }\end{array}$ \\
\hline $\begin{array}{l}\text { Edward } \\
\text { syndrome }\end{array}$ & $1 / 6000$ & Trisomy 13 & Typically sporadic (RR = s1\%) & $\begin{array}{l}\text { ASD, PDA, polyvalvular } \\
\text { disease, VSD (80-100\%) }\end{array}$ \\
\hline $\begin{array}{l}\text { Patau } \\
\text { syndrome }\end{array}$ & $\begin{array}{l}1 / 10,000- \\
1 / 20,000\end{array}$ & Trisomy18 & Typically sporadic (RR = s1\%) & $\begin{array}{l}\text { ASD, PDA, polyvalvular } \\
\text { disease, VSD (80-100\%) }\end{array}$ \\
\hline \multicolumn{5}{|c|}{ Microdeletion/duplication syndromes } \\
\hline $\begin{array}{l}\text { 22q11.2 } \\
\text { microdeletion } \\
\text { syndrome }\end{array}$ & $1 / 4,000$ & 22q11.2 deletion & $\begin{array}{l}\text { Majority de novo, AD when } \\
\text { inherited (RR }=50 \%)\end{array}$ & $\begin{array}{l}\text { Conotruncal defects: IAA } \\
\text { type B, TrA, TOF, VSD } \\
(75-80 \%)\end{array}$ \\
\hline $\begin{array}{l}\text { Willams- } \\
\text { Beuren } \\
\text { syndrome }\end{array}$ & $\begin{array}{l}1 / 7,500- \\
1 / 20,000\end{array}$ & $\begin{array}{l}\text { 7q11.23 del, incl. } \\
\text { ELN gene }\end{array}$ & $\begin{array}{l}\text { Majority de novo, AD when } \\
\text { inherited (RR }=50 \%)\end{array}$ & $\begin{array}{l}\text { AS (especially SVAS), } \\
\text { PPS, valve defects (80- } \\
100 \%)\end{array}$ \\
\hline \multicolumn{5}{|c|}{ Singe gene disorders } \\
\hline $\begin{array}{l}\text { Noonan or } \\
\text { Noonan-like } \\
\text { syndrome }\end{array}$ & $\begin{array}{l}1 / 1,000 \\
1 / 2,500\end{array}$ & $\begin{array}{l}\text { PTPN11, SOS1, } \\
\text { RAF1, KRAS, } \\
\text { HRAS, NRAS, } \\
\text { BRAF, MAP2K1, } \\
\text { MAP2K2, SHOC2 }\end{array}$ & $\begin{array}{l}25-70 \% \text { de novo, AD when } \\
\text { inherited }(R R=50 \%) \text {, rarely } \\
\text { AR (RR }=25 \%) \text {. }\end{array}$ & $\begin{array}{l}\text { ASD, HCM, PDA, PS, } \\
\text { VSD (80-90\%) }\end{array}$ \\
\hline CHARGE & $\begin{array}{l}1 / 8,500- \\
1 / 10,000\end{array}$ & CHD7, SEMA3E & $\begin{array}{l}\text { Majority de novo, AD when } \\
\text { inherited (RR }=50 \%)\end{array}$ & ASD, TOF, VSD (50-85\%) \\
\hline $\begin{array}{l}\text { Holt-Oram } \\
\text { syndrome }\end{array}$ & $1 / 100,000$ & TBX5 & $\begin{array}{l}\text {-85\% de novo, AD } \\
(\mathrm{RR}=50 \%)\end{array}$ & $\begin{array}{l}\text { ASD, conduction defects } \\
\text { VSD }(75-85 \%)\end{array}$ \\
\hline $\begin{array}{l}\text { Alagille } \\
\text { syndrome }\end{array}$ & $1 / 100,000$ & JAG1, NOTCH2 & $\begin{array}{l}50-70 \% \text { de novo, AD (RR = } \\
50 \%)\end{array}$ & $\begin{array}{l}\text { AS, ASD, PPS, PS TOF, } \\
\text { VSD (85-95\%) }\end{array}$ \\
\hline $\begin{array}{l}\text { Costello } \\
\text { syndrome }\end{array}$ & $\begin{array}{l}1 / 300,000- \\
1 / 1,250,000\end{array}$ & HRAS & $\begin{array}{l}\text { Majority de novo, AD when } \\
\text { inherited (RR }=50 \%)\end{array}$ & $\begin{array}{l}\text { Arrhythmias, HCM, PS } \\
(>60 \%)\end{array}$ \\
\hline $\begin{array}{l}\text { Char } \\
\text { syndrome }\end{array}$ & $\begin{array}{l}\text { Unknown, } \\
\text { rare }\end{array}$ & TFAP2B & $\begin{array}{l}\% \text { de novo unknown, AD when } \\
\text { inherited (RR }=50 \%)\end{array}$ & PDA (100\%) \\
\hline $\begin{array}{l}\text { Cardiofaciocu } \\
\text { taneous } \\
\text { syndrome }\end{array}$ & $\begin{array}{l}\text { Unknown, } \\
\text { rare }\end{array}$ & $\begin{array}{l}\text { BRAF, MAP2K1, } \\
\text { MAP2K2, KRAS }\end{array}$ & $\begin{array}{l}\text { Majority de novo, AD when } \\
\text { inherited (RR }=50 \%)\end{array}$ & $\begin{array}{l}\text { ASD, HCM, PS, VSD } \\
(\sim 70 \%)\end{array}$ \\
\hline
\end{tabular}

Data from ${ }^{19,99}$ and Genereviews ${ }^{8}$

${ }^{1}$ Abbreviations: $A D=$ autosomal dominant, $A R=$ autosomal recessive

${ }^{2}$ Abbreviations: $\mathrm{AS}=$ aortic stenosis, $\mathrm{ASD}=$ atrial septal defect, $\mathrm{AVC}=$ atrioventricular canal, $\mathrm{BAV}=$ bicuspid aortic valve disease, $\mathrm{CoA}=$ coarctation of the aorta, $\mathrm{HCM}=$ hypertrophic cardiomyopathy, HLHS = hypoplastic left heart syndrome, IAA = interrupted aortic arch, PAPVD = partial anomalous pulmonary venous drainage, $\mathrm{PDA}=$ patent ductus arteriosus, $\mathrm{PPS}=$ peripheral pulmonary stenosis, $\mathrm{PS}=$ pulmonary stenosis, SVAS = supravalvular aortic stenosis, $\mathrm{TrA}=$ truncus arteriosus, TOF = Tetralogy of Fallot, VSD $=$ ventricular septal defect. 
Table 5: Recurrence risks for isolated (non-syndromic) CHDs (\%)

\begin{tabular}{|c|c|c|c|c|}
\hline Defect & Father Affected & Mother Affected & 1 Sibling Affected & 2 Siblings Affected \\
\hline ASD & $1.5-3.5$ & $4-6$ & $2.5-3$ & 8 \\
\hline AVSD & $1-4.5$ & $11.5-14$ & $3-4$ & 10 \\
\hline VSD & $2-3.5$ & $6-10$ & 3 & 10 \\
\hline AS & $3-4$ & $8-18$ & 2 & 6 \\
\hline PS & $2-3.5$ & $4-6.5$ & 2 & 6 \\
\hline TOF & 1.5 & $2-2.5$ & $2.5-3$ & 6 \\
\hline CoA & $2-3$ & $4-6.5$ & 2 & 10 \\
\hline PDA & $2-2.5$ & $3.5-4$ & 3 & 6 \\
\hline HLHS & \multicolumn{2}{|c|}{$21^{48}$} & 2 & NR \\
\hline TGA & \multicolumn{2}{|c|}{$2^{97}$} & 1.5 & 3 \\
\hline L-TGA & \multicolumn{2}{|c|}{$3-5^{97}$} & $5-6$ & 3 \\
\hline EA & NR & 697 & 1 & 3 \\
\hline TrA & NR & NR & 1 & 3 \\
\hline TA & NR & NR & 1 & 1 \\
\hline PA & NR & NR & 1 & \\
\hline
\end{tabular}

Data from ${ }^{52-54}$ except where otherwise noted. NR = not reported/insufficient data

Merged cells indicate recurrence when one parent is affected, irrespective of gender, and are used in the absence of gender-stratified risks.

Abbreviations: $A S D=$ atrial septal defect, $A S=$ aortic stenosis, $A V S D=$ atrioventricular septal defect, $C o A$ = coarctation of the aorta, EA = Ebstein's Anomaly, HLHS = hypoplastic left heart syndrome, L-TGA = congenitally corrected transposition of the great arteries, PDA = patent ductus arteriosus, PA = pulmonary atresia, $\mathrm{PS}=$ pulmonary stenosis, $\mathrm{TA}=$ tricuspid atresia, $\mathrm{TGA}=$ transposition of the great arteries, $\mathrm{TOF}=$ Tetralogy of Fallot, TrA = truncus arteriosus, VSD = ventricular septal defect 
Table 6: Types of Genetic Tests for CHDs

\begin{tabular}{|c|c|c|c|c|}
\hline Test & Type & Target & Resolution & Detects \\
\hline Karyotyping & Cytogenetic & Genome & $>10 \mathrm{Mb}$ & $\begin{array}{c}\text { Aneuploidies, chromosomal } \\
\text { abnormalities }\end{array}$ \\
\hline $\mathrm{FISH}$ & Cytogenetic & $\begin{array}{l}\text { Chromosomal } \\
\text { region }\end{array}$ & $>20 \mathrm{~kb}$ & $\begin{array}{c}\text { Aneuploidies, chromosomal } \\
\text { abnormalities }\end{array}$ \\
\hline $\begin{array}{l}\text { CMA (aCGH, } \\
\text { SNP arrays) }\end{array}$ & Molecular & Genome & $5 \mathrm{kbp}$ & $\begin{array}{c}\text { SNPs, CNVs and other } \\
\text { submicroscopic rearrangements }\end{array}$ \\
\hline WGS/WES & Molecular & Genome/Exome & Single-base & SNPs, indels, CNVs ${ }^{1}$ \\
\hline
\end{tabular}

${ }^{1}$ Detection of indels and CNVs can be difficult using current technology. Bioinformatics capabilities are emerging. Abbreviations: aCGH = array comparative genomic hybridization, $\mathrm{CMA}=$ chromosome microarray analysis, CNVs = copy number variants, FISH = fluorescence in situ hybridization, SNPs = single nucleotide polymorphisms, WES

= whole exome sequencing, WGS = whole genome sequencing 